Ciência Florestal, Santa Maria, v. 21, n. 1, p. 93-102, jan.-mar., 2011

\title{
CONSERVAÇÃO DE SEMENTES DE MARIZEIRO Geoffroea spinosa Jacq. UTILIZANDO DIFERENTES EMBALAGENS E AMBIENTES
}

\author{
CONSERVATION OF MARIZEIRO Geoffroea spinosa Jacq. SEEDS \\ USING DIFFERENT PACKAGINGS AND ENVIRONMENTS
}

\author{
Vênia Camelo de Souza ${ }^{1}$ Leonaldo Alves de Andrade ${ }^{2}$ Flávio Ricardo da Silva Cruz ${ }^{3}$ \\ Juliano Ricardo Fabricante ${ }^{4}$ Lamartine Soares Bezerra de Oliveira ${ }^{5}$
}

\begin{abstract}
RESUMO
O marizeiro (Geoffroea spinosa Jacq.) é uma espécie florestal importante, sobretudo por ser adaptada às condições de matas ciliares do semi-árido e ecossistemas associados, ocorrendo em vastas áreas do Nordeste brasileiro e no vale do rio São Francisco, sempre restrita a ambientes sazonalmente inundados. Este trabalho teve como objetivos avaliar o efeito de diferentes tipos de embalagens e do período de armazenamento sobre o processo germinativo e o vigor de sementes de Geoffroea spinosa Jacq. acondicionadas também em diferentes ambientes. O experimento foi instalado no Laboratório de Ecologia Vegetal do CCA/UFPB, seguindo um delineamento inteiramente casualizado. As sementes foram distribuídas em dois ambientes (condições naturais, no laboratório e câmara fria), acondicionadas em dois tipos de embalagens (sacos de papel e sacos plásticos) durante cinco períodos de armazenamento: 0, 15, 30, 60 e 90 dias. Foram avaliados o teor de água, o índice de velocidade de emergência, a massa seca e o comprimento de plântulas. Os dados foram submetidos à análise de regressão polinomial. Na embalagem plástica e no ambiente de câmara fria, houve menor redução da viabilidade e do vigor ao longo do armazenamento. As sementes acondicionadas em sacos de papel e armazenadas em ambiente de laboratório perderam rapidamente a viabilidade e o vigor a partir dos 30 dias de armazenamento.
\end{abstract}

Palavras-chave: matas ciliares; sementes florestais; armazenamento; viabilidade.

\begin{abstract}
Geoffroea spinosa Jacq., commonly known as marizeiro in Brazil, is an important tree species, mainly because it is adapted to riparian forest conditions in semi-arid and associated ecosystems. The species occur in large areas of northeastern Brazil and in the São Francisco river valley, always restricted to seasonally flooded environments. This study aimed to evaluate the effect of different types of packaging and storage periods, as well the influence of environments on the process of seed germination and vigor of Geoffroea spinosa. The experiment was carried out at the Laboratory of Plant Ecology - CCA/UFPB, following a completely randomized design. The seeds were distributed among two environments (natural conditions in the laboratory and cold room), packed in two types of packaging (paper bags and plastic bags) for five periods of storage: $0 ; 15 ; 30 ; 60$ and 90 days. Water content, the emergence velocity index, dry weight and length of seedlings were evaluated. The data were submitted to a polynomial regression analysis. In plastic packaging and the environment of the cold room there was less reduction of viability and vigor during
\end{abstract}

1. Bióloga, Doutoranda em Agronomia, Centro de Ciências Agrárias, Universidade Federal da Paraíba, Laboratório de Ecologia Vegetal, CEP 58397-000, Areia (PB).venia@cft.ufpb.br

2. Engenheiro Agrônomo, Professor Associado do Departamento de Fitotecnia, Centro de Ciência Agrárias, Universidade Federal da Paraíba, Laboratório de Ecologia Vegetal, CEP 58397-000, Areia (PB). landrade@cca.ufpb.br.

3. Graduando em Agronomia do Centro de Ciências Agrárias, Universidade Federal da Paraíba, Laboratório de Ecologia Vegetal, CEP 58397-000,Areia (PB). flricardocruz@hotmail.com

4. Biólogo, Doutorando em Agronomia, Centro de Ciência Agrárias, Universidade Federal da Paraíba, Laboratório de Ecologia Vegetal, CEP 58397-000, Areia (PB). julianofabricante@hotmail.com.br.

5. Engenheiro Agrônomo, Mestrando em Ciências Florestais pela Universidade Federal Rural de Pernambuco, CEP 52191-900, Recife (PE). soareslt@hotmail.com

Recebido para publicação em 11/09/2009 e aceito em 8/06/2010. 
storage. Seeds packed in paper bags and stored in a laboratory rapidly lost viability and vigor, after 30 days of storage.

Keywords: riparian forests; forest seeds; storage; viability.

\section{INTRODUÇÃO}

A espécie Geoffroea spinosa Jacq. popularmente conhecida como mari ou marizeiro, tem ocorrência natural em matas ciliares e ambientes inundáveis, como lagoas e áreas depressionárias, em vastas áreas do semiárido e ecossistemas associados, sendo também registrada em parte da Região CentroOeste do Brasil. Dotados de espinhos, os indivíduos adultos atingem altura entre seis e $12 \mathrm{~m}$, apresentam copa alongada com arquitetura muito particular. A madeira é moderadamente pesada, medianamente resistente podendo ser empregada na fabricação de móveis rústicos, além de lenha e carvão (LORENZI, 1998).

Por ser adaptada às condições de matas ciliares e ambientes inundáveis e também por produzir frutos apreciados por muitos animais, essa espécie assume uma importância singular na silvicultura conservacionista. Considere-se que as matas ciliares historicamente vêm sofrendo forte pressão antrópica, o que praticamente as dizimou ao longo da maioria dos rios brasileiros. Essa realidade é particularmente válida na região Nordeste, não obstante sejam tais ambientes, legalmente protegidos e constituídos como Áreas de Preservação Permanente. Ressalte-se também que as espécies endêmicas, ou de ocorrência restrita a determinados habitats, como é o caso de Geoffroea spinosa tornamse muito mais vulneráveis à extinção, sobretudo quando seus nichos de ocorrência são ocupados ou profundamente alterados pela ação antrópica. Não obstante a sua importância, Geoffroea spinosa é muito pouco estudada, praticamente não havendo estudos relacionados ao comportamento de suas sementes no que se refere à capacidade germinativa após o armazenamento. Faltam, igualmente, informações básicas que subsidiem a formulação de um protocolo para a produção de mudas dessa espécie.

Nesse contexto, pesquisas relacionadas ao armazenamento de sementes, à manutenção do seu poder germinativo e, consequentemente, à produção de mudas de espécies florestais autóctones se revestem de importância fundamental, diante dos grandes desafios impostos pela antropização e pela perda de biodiversidade nos principais biomas do planeta.
A sazonalidade, a irregularidade espacial e temporal na produção de sementes pelas espécies nativas e, especialmente, as dificuldades encontradas para armazenar e conservar esses propágulos constituem grandes obstáculos à produção de mudas florestais. Portanto, conhecer as exigências das espécies, no que se refere ao armazenamento das sementes permite a adoção de técnicas adequadas e necessárias à conservação desses táxons. Portanto, o controle da qualidade fisiológica, associado à preservação da viabilidade e à manutenção do vigor das sementes por um tempo prolongado, constitui conhecimentos essenciais para a conservação ex situ e in situ. Assim sendo, as pesquisas com armazenamento de sementes florestais são, para muitas espécies, a base para a produção de mudas e, por conseguinte, para a conservação destas (MATOS et al., 2008; AZEVEDO et al., 2003).

No armazenamento de sementes florestais, o processo de deterioração não pode ser evitado, entretanto, o correto armazenamento pode ajudar a controlar a velocidade de deterioração dos referidos propágulos. Dependendo das condições ambientais e das características das próprias sementes, essa deterioração pode se dar de forma muito rápida ou ser consideravelmente retardada, com ganhos significativos na adequação dos programas de produção de mudas e de reflorestamento (VIEIRA et al.,2001; TAKAHASHI et al., 2009). Para ALVES et al. (2008), diversas técnicas em busca de condições ideais de armazenamento estão sendo frequentemente estudadas, entretanto, a principal ainda é a redução do seu metabolismo tanto por meio da remoção de água como pela diminuição da temperatura. O período de armazenamento de sementes florestais associados a diferentes tipos de embalagens são pontos de extrema importância para a manutenção de sua viabilidade uma vez que cada espécie pode apresentar comportamentos completamente distintos diante das mesmas condições.

O armazenamento de sementes constitui uma estratégia de conservação ex situ dentre as mais utilizadas, contribuindo para a preservação das características genéticas até o processo de semeio (CARNEIRO, 1985; NODARI et al., 1998). O tipo de embalagem é outro fator de extrema importância no processo de armazenamento de sementes

Ci. Fl., v. 21, n. 1, jan.-mar., 2011 
florestais, pois também estará influenciando na capacidade de conservação do poder germinativo desses propágulos. Segundo Marcos Filho (2005), os recipientes influenciam nas trocas de umidade entre as sementes e o meio, ressaltando-se que esses fatores externos como a própria umidade e a temperatura influenciam diretamente na longevidade desses propágulos, particularmente naqueles classificados como recalcitrantes (COPELAND, 1976).

Diante do exposto e considerando a carência de estudos relacionados à espécie em questão, este trabalho teve como objetivo estudar a influência de diferentes embalagens e condições de armazenamento sobre a germinação e o vigor de sementes de Geoffroea spinosa Jacq.

\section{MATERIAL E MÉTODOS}

As sementes de Geoffroea spinosa foram extraídas de frutos maduros coletados sob árvores matrizes localizadas na zona rural do município de Gurinhém, PB ( $7^{\circ} 11^{\prime} 31,3$ ” S, 35 31' 7,2” $\mathrm{W}-147$ $\mathrm{m}$ de altitude), em junho de 2008 . O experimento foi conduzido no período de julho a outubro de 2008 no Laboratório de Ecologia Vegetal (LEV), no Centro de Ciências Agrárias (CCA) da Universidade Federal da Paraíba. Antes da instalação do experimento, as sementes foram beneficiadas, procedendo-se à limpeza manualmente utilizando-se água e peneiras. Após o beneficiamento, as sementes foram postas para secar à sombra.

Após a secagem inicial, as sementes foram acondicionadas em sacos de papel $(39,5 \times 17,5 \mathrm{~cm})$ e de polietileno $(38,4 \times 24,0 \mathrm{~cm})$, e distribuídas em dois ambientes: condição de Laboratório, (Temperatura máxima e mínima, $23,5^{\circ} \mathrm{C}$ e $19,2^{\circ} \mathrm{C}$ e Umidade relativa média de $85 \%$, dados da Estação Meteorológica do CCA/UFPB, Areia, PB) e câmara fria, (temperatura oscilando entre 2 e $4^{\circ} \mathrm{C}$ e umidade relativa média de $75 \%$ ). Foram avaliados cinco tempos de armazenamento: 0, 15, 30, 60 e 90 dias. Em cada período de armazenamento, as sementes procedentes de cada tratamento foram submetidas à determinação do teor de água e ao teste de germinação. Procedeu-se à determinação de umidade das sementes tomando por base o método de estufa a $105 \pm 3^{\circ} \mathrm{C}$, durante 24 horas (BRASIL, 1992), utilizando-se $77 \mathrm{~g}$ de sementes por repetição, com quatro repetições.

Para a avaliação da porcentagem de emergência foi instalado um experimento em casa de vegetação, no qual as sementes foram dispostas em bandejas de polietileno ( $48,5 \mathrm{~cm}$ de comprimento, 33 $\mathrm{cm}$ de largura e $6,6 \mathrm{~cm}$ de profundidade), utilizandose como substrato areia lavada e autoclavada. A porcentagem de emergência foi calculada de acordo com Laboriau e Valadares (1976). A contagem das plântulas emergidas foi efetuada diariamente durante 23 dias. Além desse parâmetro foi determinado o índice de velocidade de emergência pela fórmula proposta por Popinigis (1985). Depois de realizados os testes de emergência, foram separados e medidos, utilizando-se uma régua graduada em centímetros, os comprimentos da parte aérea e das raízes das plântulas. Após serem devidamente medidas, parte aérea e raiz foram postas separadamente em sacos de papel e acondicionadas em estufa com circulação forçada de ar a $65^{\circ} \mathrm{C}$ até atingirem peso constante, determinando-se assim a massa seca das plântulas.

Foi empregado o delineamento inteiramente casualizado, em parcelas subdivididas, com fatorial na parcela (embalagens $\mathrm{x}$ ambientes) e análise no tempo (períodos) para a subparcela. Os dados foram submetidos à análise de variância, teste de Tukey $(p \leq 0,05)$ e regressão polinomial, utilizando-se o programa SISVAR (FERREIRA, 2007).

\section{RESULTADOS E DISCUSSÃO}

A tabela 1 mostra a análise estatística dos fatores analisados com o grau de significância.

De acordo com as curvas ajustadas para o índice de velocidade de emergência (Figura 1), os dados revelam, na análise de regressão, efeito quadrático para as sementes de Geoffroea spinosa acondicionadas nos dois tipos de embalagens (papel e plástico). Pela análise dos gráficos, observa-se um comportamento semelhante quanto à tendência na diminuição do vigor aos 90 dias de armazenamento para sementes armazenadas tanto em ambiente de laboratório quanto em câmara fria, independente do tipo de embalagem. Sementes acondicionadas em embalagem de plástico, tanto armazenadas em ambiente de laboratório quanto em câmara fria, apresentaram maior vigor, com queda expressiva aos 90 dias de armazenamento. Sementes armazenadas em embalagem de papel e em ambientes de laboratório mostraram-se mais vigorosas aos 15 dias de armazenamento, condição essa, que não foi mantida para os demais períodos (30, 60 e 90 dias) de armazenamento.

De acordo com Santos e Paula (2009), a avaliação do vigor permite a detecção de possíveis 
TABELA 1: Quadrados médios e coeficientes de variação (CV) referentes ao índice de velocidade de emergência (IVE), porcentagem de emergência $(\% \mathrm{E})$, teor de água $(\% \mathrm{U})$, comprimento da parte aérea (CPA), comprimento da raiz (CR), massa seca da parte aérea (MSPA) e massa seca da raiz (MSR), de plântulas provenientes de sementes de Geoffroea spinosa armazenadas em dois ambientes (laboratório e câmara fria), em dois tipos de embalagens (saco de papel e saco plástico) durante cinco períodos de armazenamento $(0,15,30,60$ e 90 dias).

TABLE 1: Mean squares and coefficient of variation (VC) for the emergence velocity index (IVE), emergence percentage $(\% \mathrm{E})$, water content $(\% \mathrm{U})$, length of crown (CPA), length of root (CR), dry mass of crown (MSPA) and dry mass of root (MSR) of seedlings of Geoffroea spinosa from seeds stored in two environments (Laboratory and cold room) and two types of packaging (paper bags and plastic bags) for four storage periods $(0,15,30,60$ and 90 days).

\begin{tabular}{lcccccccc}
\hline \multirow{2}{*}{ FV } & \multirow{2}{*}{ GL } & \multicolumn{7}{c}{ Quadrados médios } \\
\cline { 3 - 8 } & & IVE & $\%$ E. & \%U. & CPA & CR & MSPA & MSR \\
\hline Ambiente & 1 & 0,033 & 30,250 & $92,833^{*}$ & $32,165^{*}$ & 221,673 & 2,526 & 0,008 \\
Embalagem & 1 & $0,505^{*}$ & $1980,25^{*}$ & $695,24^{*}$ & $196,05^{*}$ & $676,141^{*}$ & $55,507^{*}$ & $55,49^{*}$ \\
Amb. x Emb. & 1 & 0,015 & 6,25 & $298,59^{*}$ & 1,971 & 6,488 & 2,069 & 5,096 \\
Erro 1 & 12 & 0,031 & 242,25 & 1,768 & 4,410 & 47,257 & 2,173 & 1,144 \\
Período & 3 & $0,895^{*}$ & $8884,91^{*}$ & $52,077^{*}$ & $441,08^{*}$ & $1249,04^{*}$ & $60,345^{*}$ & 31,317 \\
Per. x Amb. & 3 & $0,034^{*}$ & $402,916^{*}$ & $3,545^{*}$ & $11,846^{*}$ & $122,502^{*}$ & 1,429 & $3,351^{*}$ \\
Per. x Emb. & 3 & $0,262^{*}$ & $2108,91^{*}$ & $67,800^{*}$ & $69,012^{*}$ & $450,477^{*}$ & $16,121^{*}$ & $28,72^{*}$ \\
Per.xAmb.xEmb. & 3 & $0,057^{*}$ & $652,25^{*}$ & $25,431^{*}$ & $11,361^{*}$ & $205,191^{*}$ & $6,269^{*}$ & $5,510^{*}$ \\
Erro 2 & 36 & 0,005 & 47,361 & 1,3135 & 3,700 & 36,121 & 0,898 & 0,383 \\
\hline CV1 & - & 52,88 & 50,11 & 4,49 & 25,12 & 40,63 & 54,42 & 50,01 \\
CV2 & - & 22,77 & 22,16 & 3,87 & 23,01 & 35,52 & 34,99 & 28,94 \\
\hline
\end{tabular}

*Valor de F significativo a $5 \%$ de probabilidade

(A)

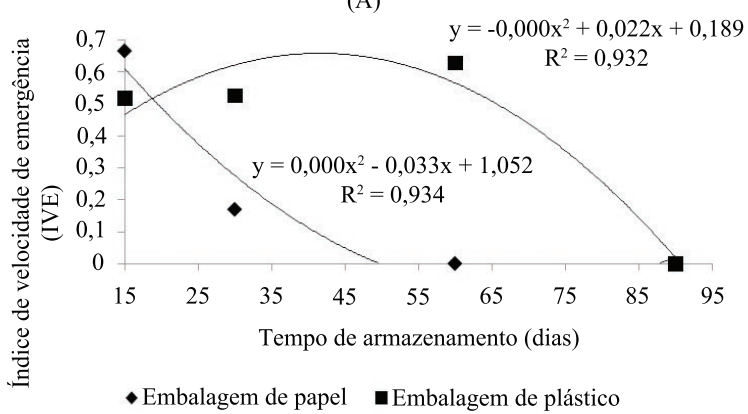

(B)

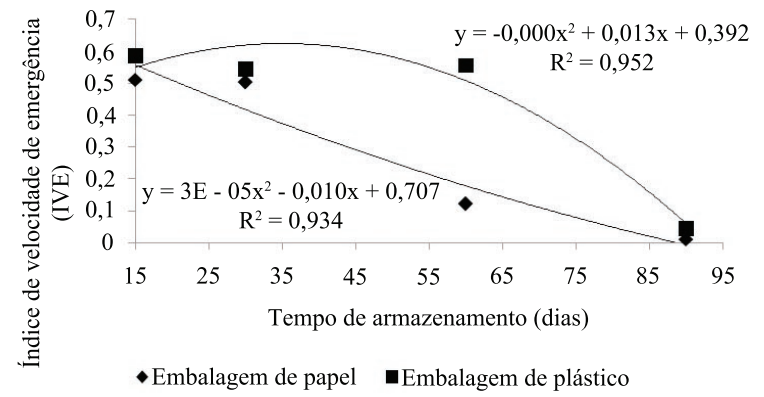

FIGURA 1: Índice de Velocidade de Emergência de sementes de Geoffroea spinosa (A = ambiente de laboratório, $\mathrm{B}=$ câmara fria).

FIGURE 1: Velocity Emergency Index of Geoffroea spinosa seeds (A = laboratory environment, B = cold room).

diferenças na qualidade fisiológica de lotes que apresentam poder germinativo semelhante $\mathrm{e}$ que podem exibir comportamentos distintos, em condição de campo ou mesmo durante o armazenamento.

Já sementes acondicionadas em embalagem de papel e armazenadas em câmara fria mantiveram índice de velocidade de emergência estatisticamente igual aos 15 e 30 dias de armazenamento com posterior queda para os períodos subsequentes. Souza et al. (2005) constataram que sementes de ipê-amarelo acondicionadas em embalagens de papel e polietileno e armazenadas no ambiente de laboratório apresentaram maior perda de vigor ao longo do armazenamento. Esse comportamento se justifica pelas maiores oscilações de temperatura e de umidade a que as sementes estiveram submetidas naquele tipo de ambiente, o que interferiu na atividade metabólica destas, reduzindo sua longevidade.

As sementes de Geoffroea spinosa foram armazenadas com teor de água de 34,16\%, observando um aumento desse parâmetro para as sementes armazenadas em ambiente natural em saco de plástico, chegando ao seu valor máximo aos 90 dias de armazenamento (35,2\%) e menor valor 
registrado para sementes também armazenadas em ambiente natural, porém, em saco de papel $(16,96 \%)$ (Figura 2). Para as sementes armazenadas em ambiente de câmara fria e acondicionadas em embalagem de plástico, os valores do teor de água não diferiram estatisticamente entre si, havendo pouca oscilação. Nas sementes acondicionadas em embalagens de papel e armazenadas em câmara fria, observa-se (Figura 2) que, nos três primeiros períodos de armazenamento, houve um decréscimo gradual seguido por um leve aumento aos noventa dias de armazenamento.

Houve uma maior conservação da umidade para sementes acondicionadas em embalagem de plástico tanto para lotes de sementes armazenadas em ambiente de laboratório quanto para lotes oriundos de câmara fria, diferentemente de sementes armazenadas em embalagens de papel (Figura 2). A preservação da qualidade fisiológica de sementes sob determinadas condições ambientais de temperatura e umidade relativa do ar é influenciada pelo tipo de embalagem utilizada. Assim, as embalagens impermeáveis, como os sacos de polietileno, impedem total ou parcialmente o intercâmbio de umidade entre as sementes e o meio externo (VILLELA e PERES, 2004).

Observa-se, nas curvas de porcentagem de emergência, um ajuste quadrático para sementes armazenadas em ambiente de laboratório e câmara fria submetidas aos dois tipos de embalagens. A germinação inicial das sementes de Geoffroea spinosa foi de $83 \%$, porém, ao longo do tempo o poder germinativo das sementes decresceu chegando a $0 \%$ aos 60 e 90 dias de armazenamento para sementes em condição de ambiente de laboratório e acondicionamento em embalagens de papel (Figura 3). Esse fato se justifica pela redução do teor de água das sementes nos períodos citados, pois de acordo com Hong e Ellis (1996) as sementes recalcitrantes não sobrevivem quando desidratadas a um teor de água entre 15 e $20 \%$. Valor pouco expressivo também foi encontrado para sementes armazenadas em ambiente de câmara fria e embalagens de papel aos 90 dias (1\%) (Figura 3). As sementes de
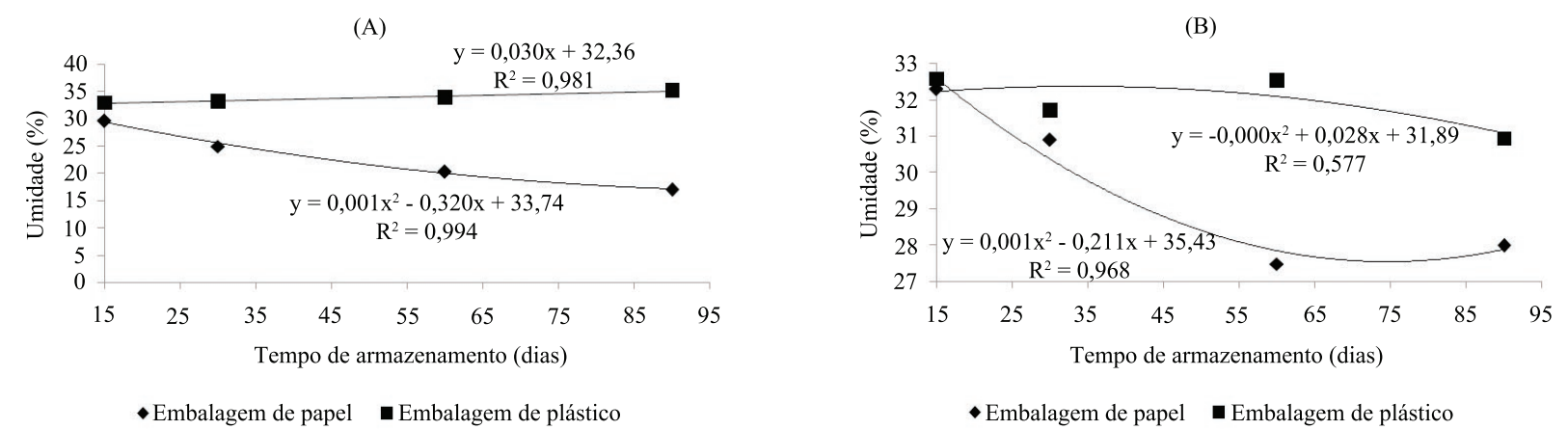

FIGURA 2: Umidade das sementes de Geoffroea spinosa em porcentagem. (A = ambiente de laboratório, $\mathrm{B}=$ câmara fria).

FIGURE 2: Water percentage content of Geoffroea spinosa seeds. $(\mathrm{A}=$ laboratory environment, $\mathrm{B}=$ cold room).

(A)

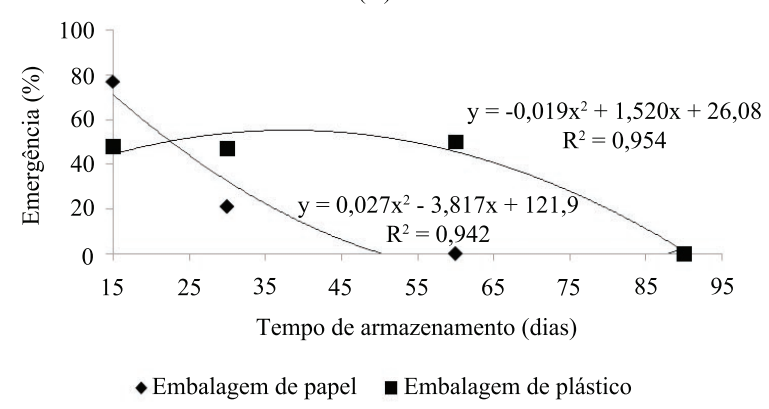

(B)

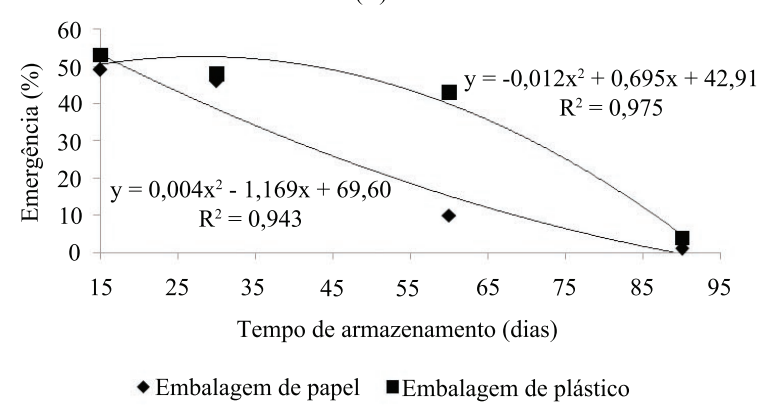

FIGURA 3: Porcentagem de emergência de plântulas de Geoffroea spinosa. (A = ambiente de laboratório, $\mathrm{B}=$ câmara fria).

FIGURE 3: Emergence Percentage of Geoffroea spinosa seedlings. (A = laboratory environment, $\mathrm{B}=$ cold room). 
Geoffroea spinosa apresentaram comportamento de sementes recalcitrantes, as quais requerem alto teor de umidade para manter a sua viabilidade por maior período de tempo (ROBERTS, 1973; CARNEIRO e AGUIAR, 1993). Diante desses resultados, podese afirmar que as sementes de Geoffroea spinosa são recalcitrantes devendo ser acondicionadas em embalagens impermeáveis e armazenadas em câmara fria por um período de, no máximo, 60 dias.

Para sementes armazenadas em embalagem plástica, houve maior porcentual de emergência nos três primeiros períodos de armazenamento ( 15 , 30 e 60 dias), independentemente dos ambientes considerados, indicando que a umidade pode ter influenciado na manutenção do vigor de sementes de Geoffroea spinosa nos períodos citados. Segundo Nazário et al. (2008) a umidade pode ser considerada um fator decisivo para manter a qualidade das sementes durante o armazenamento.

Villela e Peres (2004), afirmam que as sementes recalcitrantes não podem ser secas abaixo de determinado teor de água sem que ocorram danos fisiológicos. Os diásporos de Araucaria angustifolia perdem a viabilidade com níveis de redução de água inferiores a 37\%. Ainda de acordo com os autores citados, grande número de espécies frutíferas e florestais possui sementes recalcitrantes, o que complica a conservação do germoplasma pela dificuldade de armazenamento.

Observa-se pelos gráficos (Figura 3), que a emergência permanece praticamente constante nos períodos 15, 30 e 60 dias, não diferindo estatisticamente entre si, para sementes armazenadas em ambiente de laboratório e câmara fria acondicionadas em embalagens de plástico. Após esse período, ocorreu uma queda acentuada na emergência. Já para sementes acondicionadas em embalagem de papel tanto em condições de laboratório como em câmara fria, observa-se um decréscimo na emergência desde as primeiras avaliações, ou seja, as embalagens de plásticos proporcionaram porcentagens de germinação semelhantes durante um maior período de tempo. Kano et al. (1978), trabalhando com sementes de Ipê dourado (Tabebuia sp), constataram que a porcentagem de germinação da referida espécie se manteve próxima a inicial durante um maior período para sementes armazenadas em embalagens de plástico quando comparadas àquelas oriundas de embalagens de papel, o que eles atribuíram à lenta absorção de umidade do meio em sacos de plástico. Para esse parâmetro, houve diferença significativa para sementes armazenadas em ambiente de laboratório em sacos de papel, o que pode ser observado por uma diminuição brusca na porcentagem de emergência do período 30 para 60 dias. $\mathrm{O}$ ambiente de laboratório associado com a embalagem de papel foi o mais prejudicial à germinação de Geoffroea spinosa, possivelmente por causa das variações normais de temperatura e umidade relativa do ar (MEDEIROS e ZANON, 2000). Já para as sementes armazenadas em câmara fria acondicionadas em embalagem de papel, não houve diferença significativa para sementes armazenadas até 30 dias, entretanto, ambas diferem estatisticamente dos períodos 60 e 90 dias nas mesmas condições.

A análise dos dados de comprimento de parte aérea de plântulas de Geoffroea spinosa revelou efeito quadrático para as sementes acondicionadas nos dois tipos de embalagens e nos dois ambientes de armazenamento. As plântulas resultantes de sementes armazenadas em embalagens de papel em ambientes de laboratório e câmara fria apresentaram, nos períodos de 60 e 90 dias, maior redução no vigor, mantendo essa tendência ao longo do tempo de armazenamento. Plântulas oriundas das sementes acondicionadas em embalagem plástica, armazenadas por 15, 30 e 60 dias em ambiente de laboratório, mostraramse mais vigorosas mesmo sendo estatisticamente equivalentes para esse parâmetro (Figura 4), o mesmo fato acontecendo para as plântulas provenientes de sementes armazenadas em câmara fria no mesmo tipo de embalagem. Souza et al. (2005) trabalhando com sementes de Ipê amarelo, constataram que sementes acondicionadas em embalagens de plástico e armazenadas em ambiente de câmara fria se mostraram mais vigorosas para esse parâmetro ao longo do armazenamento. Para sementes acondicionadas em embalagens de papel e armazenadas em câmara fria, observa-se um leve aumento no comprimento da parte aérea do período 15 para 60 dias de armazenamento com queda significativa aos 60 e 90 dias desse processo.

Analisando-se os dados de comprimento de raízes de plântulas de Geoffroea spinosa, observa-se que o maior valor foi obtido em plântulas oriundas de sementes armazenadas em sacos de plástico, especialmente aos 60 dias de armazenamento para os dois ambientes. Para sementes armazenadas em embalagem de papel e em ambiente de laboratório, no decorrer do período de 30 para 60 dias, houve uma drástica redução para o parâmetro analisado,

Ci. Fl., v. 21, n. 1, jan.-mar., 2011 
mantendo-se igual até os 90 dias de armazenamento (Figura 5). Já as plântulas oriundas de sementes armazenadas em embalagens de plástico, no mesmo ambiente, apresentaram um ganho de biomassa nas raízes até os 60 dias de armazenamento chegando a $32,41 \mathrm{~cm}$. No ambiente de câmara fria para plântulas provenientes de sementes armazenadas em embalagens de papel, nos primeiros três períodos de armazenamento (15, 30 e 60 dias), não houve grande oscilação nas médias para $o$ comprimento da raiz, sendo que aos 90 dias, houve uma redução significativa, indicando perda de vigor. Sementes acondicionadas em embalagens de papel e armazenadas em câmara fria tiverem um melhor comportamento quando comparadas com aquelas oriundas do mesmo tipo de embalagem, porém, armazenadas em ambiente de laboratório, mostrando que o ambiente influenciou no vigor das sementes para as condições descritas.

Quanto às sementes armazenadas em embalagem de plástico e dispostas em câmara fria, observa-se aumento de vigor a partir do aumento do comprimento da raiz até 60 dias de armazenamento $(30,45 \mathrm{~cm}) \mathrm{com}$ posterior diminuição aos 90 dias. Vieira e Carvalho (1994) afirmam que os tratamentos que apresentam maiores valores de comprimento médio de plântulas normais ou das partes destas, são considerados mais vigorosos e sementes vigorosas originam plântulas com maior taxa de crescimento, em função de apresentarem maior capacidade de translocação de suas reservas e assimilação destas pelo eixo embrionário.

Os dados referentes à massa seca da parte aérea de Geoffroea spinosa ajustaram-se ao modelo de regressão linear de efeito quadrático. Em ambiente natural, plântulas oriundas de sementes armazenadas em embalagens de papel mostraram-se com valores de massa seca de parte aérea inferiores no terceiro e quarto períodos de armazenamento (30 e 60 dias), quando comparados com a massa seca de plântulas de sementes armazenadas em sacos de plástico para os períodos acima citados e
(A)

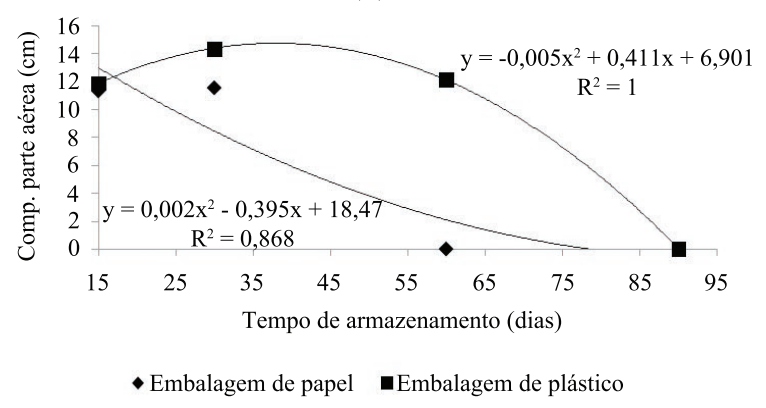

(B)

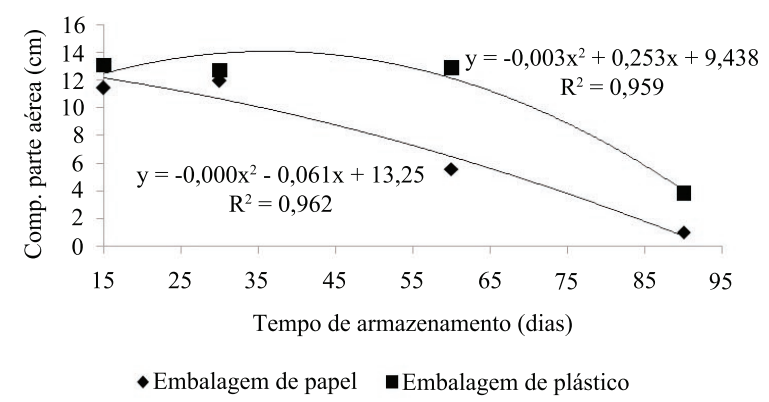

FIGURA 4: Comprimento da parte aérea de plântulas de Geoffroea spinosa. (A = ambiente de laboratório, $\mathrm{B}=$ câmara fria).

FIGURE 4: Length of the crown of Geoffroea spinosa seedlings. $(\mathrm{A}=$ laboratory environment, $\mathrm{B}=$ cold room).

(A)

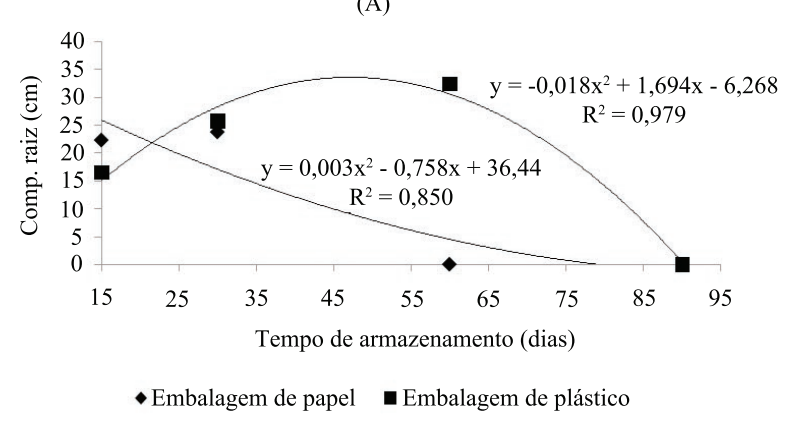

(B)

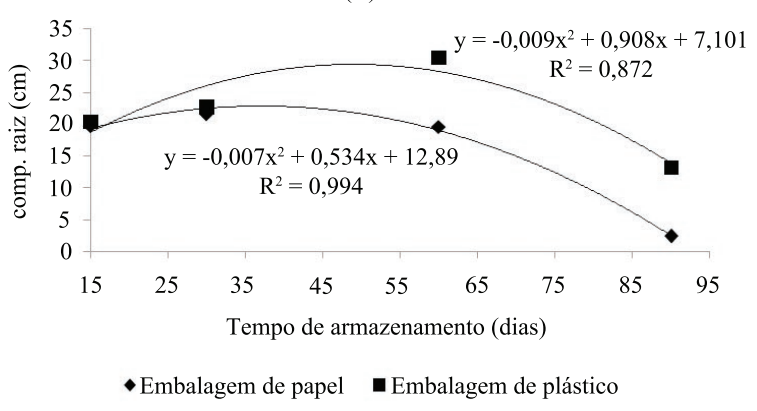

FIGURA 5: Comprimento da raiz de plântulas de Geoffroea spinosa. (A = ambiente de laboratório; B = câmara fria).

FIGURE 5: Length of roots of Geoffroea spinosa seedlings. ( $\mathrm{A}=$ laboratory environment; $\mathrm{B}=$ cold room). 
dispostas no mesmo ambiente. Observa-se, pelos gráficos (Figura 6), um crescimento nos valores de massa seca da parte aérea, dos 15 aos 60 dias de armazenamento, para sementes acondicionadas em sacos de plástico e dispostas em ambiente natural. Essas mesmas sementes apresentaram queda significativa aos 90 dias, período no qual, percebe-se um menor vigor para sementes oriundas tanto de embalagens de papel quanto das de plástico.

Plântulas oriundas de sementes armazenadas em sacos de plástico independentemente dos ambientes mostraram-se mais vigorosas do que aquelas oriundas de sementes armazenadas em sacos de papel. Esse resultado ocorreu provavelmente pelo fato do tipo de embalagem utilizada. Sacos de plásticos foram classificados, conforme Villela e Peres (2004), como impermeáveis, o que impede o intercâmbio de vapor d'água entre as sementes e o meio externo. Para sementes acondicionadas em embalagens de papel e dispostas em câmara fria, houve um discreto aumento no peso da massa seca da parte aérea dos 15 aos 30 dias de armazenamento,

(A)

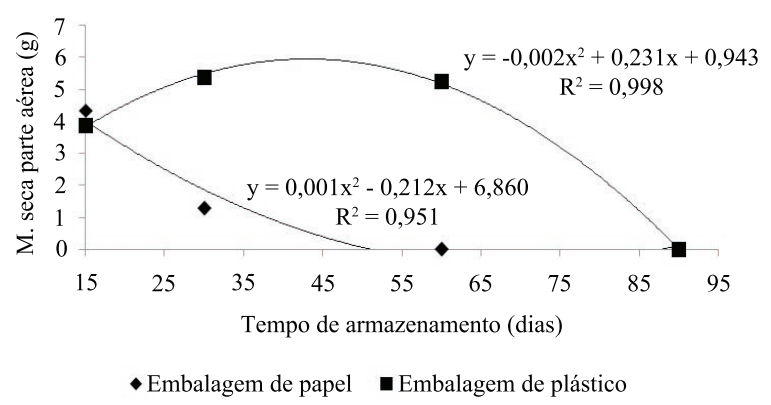

com uma queda significativa para os períodos seguintes, chegando a $0,0157 \mathrm{~g}$ aos 90 dias de armazenamento (Figura 6).

Sementes acondicionadas em embalagens de plástico e armazenadas em câmara fria apresentaram peso de massa seca de 5,56 g para sementes armazenadas até 15 dias o que correspondeu ao maior valor registrado. Nessas condições, ocorreu pouca variação para tal parâmetro nos três primeiros períodos de armazenamento havendo uma tendência a 0 aos 90 dias.

Pela análise dos dados da massa seca da raiz das plântulas de Geoffroea spinosa, observa-se que, nas embalagens de papel, houve um decréscimo desde o primeiro período de armazenamento (Figura 7). As sementes armazenadas em embalagens de plástico e em ambiente de laboratório apresentaram ganho de massa de raiz, chegando a 7,62 g para plântulas oriundas de sementes armazenadas até os 60 dias, com significativa perda de vigor aos 90 dias de armazenamento. Com isso, podese dizer que a embalagem de plástico, nos primeiros 60 dias, influenciou diretamente 0

(B)

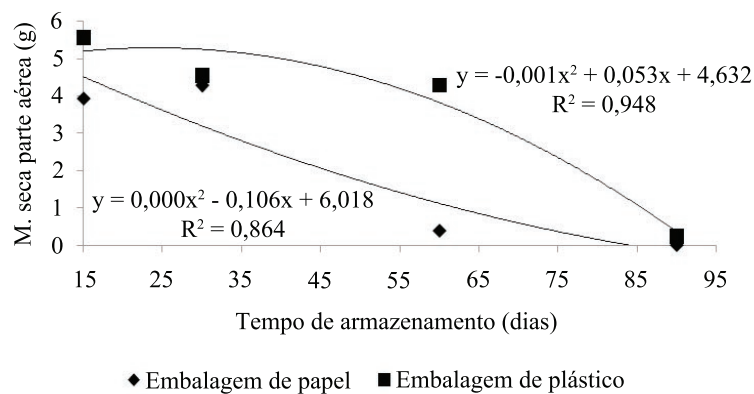

FIGURA 6: Valores da massa seca da parte aérea de plântulas de Geoffroea spinosa. (A = ambiente de Laboratório, $\mathrm{B}=$ ambiente de câmara fria).

FIGURE 6: Dry mass of crown of Geoffroea spinosa seedlings. (A = environment Laboratory; B = cold room).

(A)

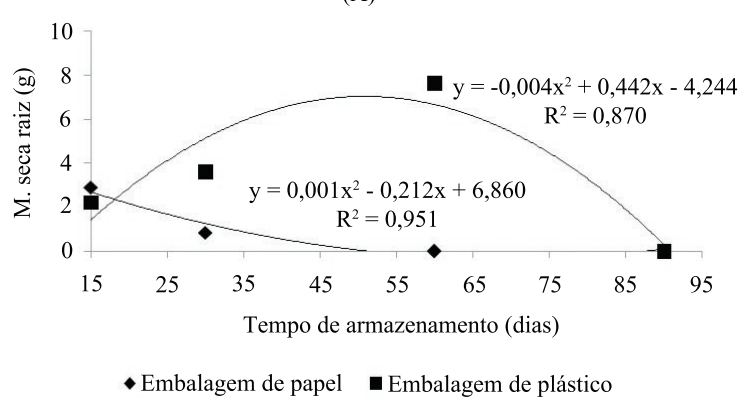

(B)

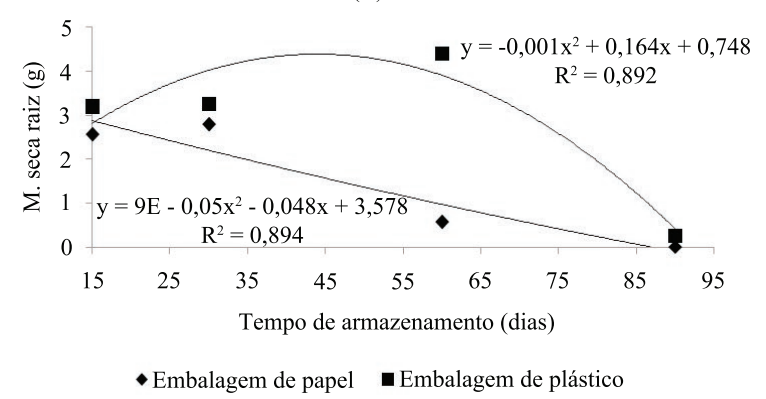

FIGURA 7: Massa seca da raiz de plântulas de Geoffroea spinosa. (A = ambiente de laboratório, B = câmara fria).

FIGURE 7: Dry mass of roots of Geoffroea spinosa seedlings. (A = laboratory environment; B = cold room).

Ci. Fl., v. 21, n. 1, jan.-mar., 2011 
vigor das plântulas oriundas de ambiente natural de laboratório.

Quanto às sementes armazenadas nas embalagens de papel e dispostas em câmara fria, observa-se um leve aumento para o parâmetro dos 15 aos 30 dias de armazenamento, com significativa redução para o período de 60 a 90 dias de armazenamento (Figura 7). Sementes armazenadas em sacos de plástico e no mesmo ambiente se mostraram estatisticamente iguais nos dois primeiros períodos de armazenamento. Nessas mesmas condições, foi registrado maior valor de massa seca de raiz $(4,392 \mathrm{~g})$, valor esse menor que o registrado aos 60 dias para sementes armazenadas em ambiente natural e em sacos de plástico. Dos 60 aos 90 dias de armazenamento, houve uma diminuição brusca na massa seca de raiz com esse parâmetro tendendo a zero para o último período citado.

\section{CONCLUSÕES}

As sementes de Geoffroea spinosa apresentaram comportamento de sementes recalcitrantes.

As sementes de Geoffroea spinosa acondicionadas em embalagens de plástico conservaram maior teor de água ao longo do armazenamento, tanto em ambiente de câmara fria, como de laboratório.

Nas embalagens plásticas e no ambiente de câmara fria, houve menor redução da viabilidade e do vigor ao longo do armazenamento.

As sementes acondicionadas nas embalagens de papel e armazenadas em ambiente de laboratório perderam rapidamente a viabilidade e o vigor, a partir dos 30 dias de armazenamento.

Para obtenção de mudas de qualidade da espécie, e conservação ex situ, recomenda-se o acondicionamento das sementes em embalagens de plástico armazenadas em câmara fria durante um período de até 60 dias.

\section{REFERÊNCIAS BIBLIOGRÁFICAS}

ALVES, E. U. et al. Comportamento fisiológico de sementes de pitombeira [Talisia esculenta (A. ST. Hil) Radlk] submetidas à desidratação. Revista Brasileira de Fruticultura, Jaboticabal, v. 30, n. 2, jun. 2008.

AZEVEDO, M. R. Q. A. et al. Influência das embalagens e condições de armazenamento no vigor de sementes de gergelim. Revista Brasileira de Engenharia Agrícola e Ambiental, Campina Grande, v. 7, n. 3, p. 519-524, 2003.

BRASIL. Ministério da Agricultura e da Reforma Agrária. Regras para análise de sementes. Brasília: SNDA/DNDV/CLAV, 1992. 365 p.

CARNEIRO, J. G. A. Armazenamento de sementes florestais. Curitiba: FUPEF, 1985. 35 p. (Série Técnica, 14).

CARNEIRO, J. G. A.; AGUIAR, I. B. Armazenamento de sementes. In: AGUIAR, I. B.; PIÑA-RODRIGUES, F. C. M.; FIGLIOLIA, M. B. Sementes florestais tropicais. Brasília: ABRATES, 1993, cap. 9. p. 333-350.

COPELAND, L. O. Principles of seed science and technology. Minnesota: Burgess. 1976. 369 p.

FERREIRA, D. F. Sisvar: Versão 5.1 (Build 72). DEX/UFLA. 2007.

HONG, T. D.; ELLIS, R. H. A protocol to determine seed storage behaviour. Rome: International Plant Genetic Resources Institute, 1996, 55 p.

KANO, N. K.; MÁRQUEZ, F.C. M.; KAGEYAMA, P. Y. Armazenamento de Sementes de Ipê- dourado (Tabebuia sp.). IPEF. n. 17, p. 13-23, 1978.

LABORIAU, L. G.; VALADARES, M. B. On the germination of seeds of Calotropis procera. Anais da Academia Brasileira de Ciências, São Paulo, v. 48, p. 174-186, 1976.

LORENZI, H. Árvores brasileiras: manual de indentificação de plantas arbóreas do Brasil. 2. ed. Nova Odessa: Instituto Plantarum, 1998. 201 p. v. 2. MARCOS FILHO, J. Deterioração de sementes In: Fisiologia de sementes: de plantas cultivadas. Piracicaba: Fealq. 2005. cap. 9. p. 165-352.

MATOS, V. P. et al. Efeito do tipo de embalagem e do ambiente de armazenamento sobre a germinação e o vigor das sementes de Apeiba tibourbou AUBL. Revista Árvore, Viçosa, v. 32, n. 4, p. 617-625, 2008.

MEDEIROS, A. C. S; ZANON, A. Armazenamento de Sementes de Sapuva (Machaerium stipitatum). Boletim de Pesquisa Florestal, Colombo, n. 40, p.57-66, jan./jun. 2000.

NAZÁRIO, P.; FERREIRA, A. N.; REBOUÇAS, E. R. Germinação de Sementes de Cynometra bauhiniifolia Benthan (jutairana) em função do dessecamento e da manutenção sob condição úmida. Acta Amazonica, v. 38, n. 3, p. 439-444, 2008

NODARI, R. O. et al. Conservação de frutos e sementes de palmiteiro (Euterpe edulis Matius) sob diferentes condições de armazenamento. Revista 
Árvore, v. 22, n. 1, p. 1-10, 1998.

POPINIGIS, F. Fisiologia da semente. Brasília: AGIPLAN, 1985. 289 p.

ROBERTS, E. H. Predicting the storage life of seeds. Seed Science and Technology. v. 1, p. 499514, 1973.

SANTOS, S. R. G.; PAULA, R. C. Testes de vigor para avaliação da qualidade fisiológica de sementes de Sebastiania commersoniana (Baill.) Smith \& Downs. Scientia Forestalis, Piracicaba, v. 37, n. 81, p. 007-016, mar. 2009.

SOUZA, V. C.; BRUNO, R. L. A.; ANDRADE, L. A. Vigor de sementes armazenadas de ipê-amarelo Tabebuia serratifolia (Vahl.) Nich. Revista Árvore, Viçosa, v. 29, n. 6, p. 833-841, 2005.
TAKAHASHI, L. S. A. T. et al. Condições de armazenamento e tempo de embebição na germinação de sementes de erva-doce (Pimpinella anissum L.). Revista Brasileira de Plantas Medicinais, Botucatu, v. 11, n. 1, p. 1-6, 2009.

VIEIRA, A. H. et al. Técnicas de produção de sementes florestais. Porto Velho: Embrapa, 2001. p. 1-4. (Documentos técnico, n. 205)

VIEIRA, R. D.; CARVALHO, N. M. Teste de vigor em sementes. Jaboticabal: FUNEP, 1994. 164 p.

VILLELA, F. A.; PERES, W. B. Coleta, beneficiamento e armazenamento. In: FERREIRA, A. G.; BORGHETTI, F. Germinação: do básico ao aplicado. Porto Alegre: Artmed, 2004. cap. 17, p.265-281.

Ci. Fl., v. 21, n. 1, jan.-mar., 2011 